\title{
Association between sarcoidosis and lymphoma revisited
}

\author{
M Karakantza, E Matutes, K MacLennan, N T J O'Connor, P C Srivastava, \\ D Catovsky
}

adhesion molecules on alveolar macrophages, and abnormal cytokine production. ${ }^{2-5}$

Here, we describe the clinical and histological features of five cases of lymphoma with a history of sarcoidosis and outline the possible mechanisms involved in the pathogenesis and coexistence of these diseases.

\section{Methods}

The hospital notes of five patients treated at The Royal Marsden Hospital, London, were reviewed and the information relevant to both diagnoses was recorded.

Biochemical features supporting the diagnosis of sarcoidosis were examined, including hypercalcaemia, lymphopenia, Kviem test, and findings in the bronchoalveolar lavage fluid. The original histological material on which the diagnosis of sarcoidosis and subsequently of lymphoma was made was also reviewed. Morphological examination of peripheral blood films and immunophenotyping by an indirect immunofluorescence technique were carried out in some cases.

\section{Case reports}

CASE 1

In 1988 a 65 year old white man presented with haemoptysis and a chest $x$ ray showed hilar and paratracheal lymphadenopathy; a lymph node biopsy specimen was reported as consistent with sarcoidosis.

Two years later, the patient developed peripheral lymphadenopathy with no other organomegaly, confirmed by computed tomography (CT) scan. A biopsy specimen of a supraclavicular node showed lymphoplasmacytic non-Hodgkin's lymphoma, low grade A according to the Working Formulation. Review of the original node histology showed a similar pattern to the second biopsy specimen. The patient was treated with six cycles of chlorambucil/prednisolone with no response, followed by five cycles of fludarabine with regression of lymphadenopathy and remains well 54 months after the diagnosis of non-Hodgkin's lymphoma.

Review of the original node histology showed a similar pattern to the second biopsy specimen. The normal architecture was diffusely replaced by sheets of a monomorphic lymphoid population (fig 1); lymphoplasmacytic differentiation was prominent and epithelioid histiocytes were easily recognised. Therefore, a diagnosis of lymphoplasmacytic lymphoma was made with no evidence of sarcoidosis in any of the biopsy specimens.
Sarcoidosis is a multisystem granulomatous disorder of uncertain origin and pathogenes lymphadenopathy or lung lesions with charvolvistic radiological changes, or both and joints is also common. ${ }^{1}$

compatible clinical and radiological features histological demonstration of non-caseating plastic diseases which may mimic sarcoidosis. ${ }^{1}$ Although the aetiology of sarcoidosis is unknown, there is evidence that this disorder is system, which may play a key pathogenetic in this disease. Manifestations of immunological dysfunction include lymphopenia, an increase in CD4 + lymphocytes expressing activation markers in the bronchoalveolar lavage fluid, increased antigen expressing capacity and 


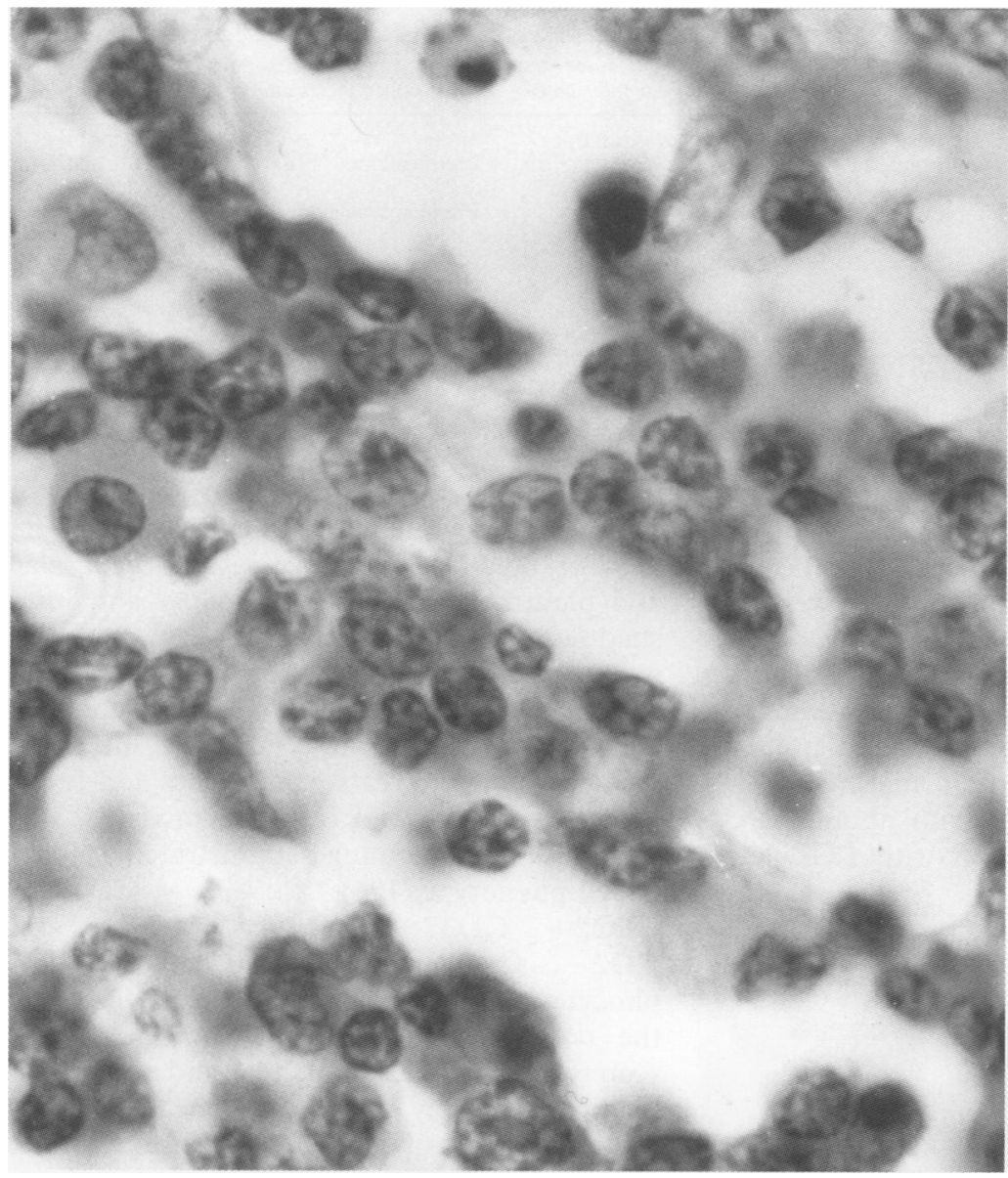

Figure 1 Section of a lymph node (case 1) showing infiltration by lymphocytes and several plasma cells.

\section{CASE 2}

In 1988 a 29 year old white woman presented with erythema nodosum, uveitis and hilar lymphadenopathy. A lymph node biopsy specimen showed non-caseating granulomas and a diagnosis of sarcoidosis was made. She was treated with prednisolone with no response.

Two years later, the patient developed B symptoms and chest $x$ ray showed a mediastinal mass. A biopsy of the mass was consistent with Hodgkin's disease, nodular sclerosis grade I.

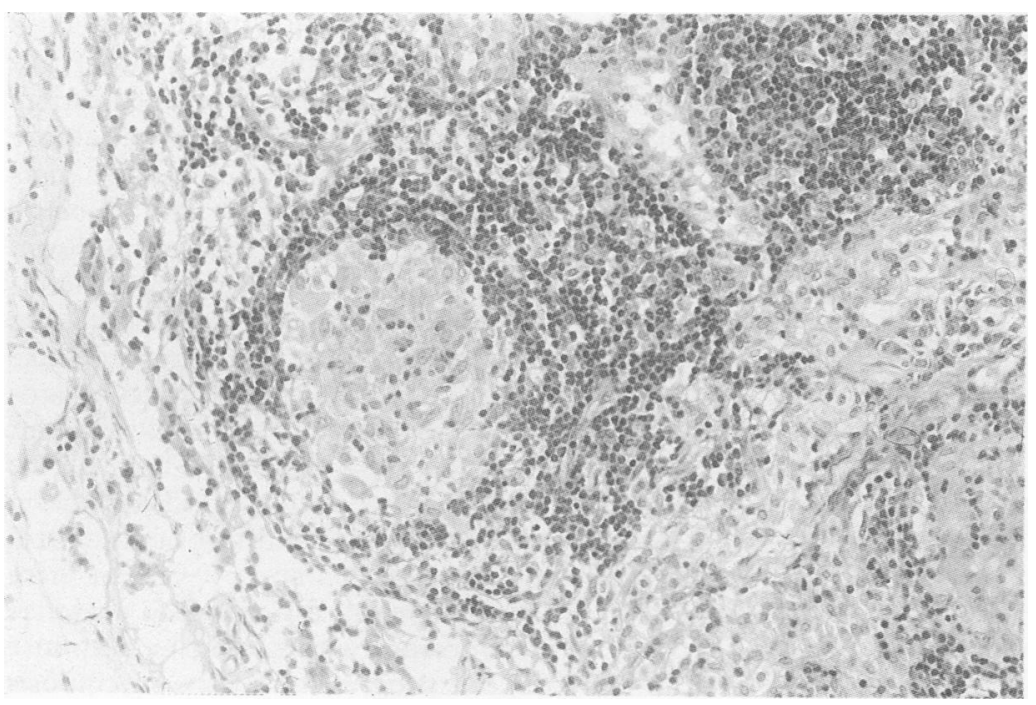

Figure 2 Section from the original lymph node (case 2) showing a non-caseating granuloma.
The histology showed a distorted architecture with numerous non-caseating granulomas, necrosis and, in addition, Reed-Sternberg and Hodgkin's cells in a lymphocyte depleted background. Review of the original histology confirmed the presence of non-caseating granulomas with no features of Hodgkin's disease (fig 2). The patient had stage IB disease and was treated with combination chemotherapy and mantle radiotherapy, achieving a complete response and is alive seven years after the diagnosis.

\section{CASE 3}

In 1958 a 34 year old Jamaican man presented with peripheral lymphadenopathy and lung shadows. A lymph node biopsy specimen showed non-caseating granulomas and a diagnosis of sarcoidosis was made. He was treated with prednisolone with good response. Subsequently, the patient developed dermal nodules, bilateral keratoconjunctivitis, recurrent parotid gland swelling, and monoarthritis. Synovial and skin biopsy specimens confirmed noncaseating granulomas consistent with sarcoid.

Twenty seven years after the diagnosis of sarcoidosis, the patient complained of weight loss, vague abdominal discomfort and symptoms related to nephrotic syndrome. An abdominal CT scan revealed a mesenteric mass $(10 \times 5 \mathrm{~cm})$ with normal sized kidneys. The histology of the mass showed diffuse infiltration by plasma cells expressing $\kappa$ light chains consistent with a diagnosis of extramedullary plasmacytoma. The renal histology showed expansion of the mesangium with $\operatorname{IgM} \kappa$ light chain positive deposits by immunostaining. Electron microscopy showed diffuse thickening of the basal membrane and expansion of the mesangium matrix with some electron dense deposits. There was no evidence of a serum monoclonal band, immunoparesis or Bence Jones protein. A skeletal survey and examination of bone marrow aspirate and a trephine biopsy specimen were normal. The patient was treated with chemotherapy (melphalan, doxorubicin, prednisolone, and lomustine), achieving a complete remission. $\mathrm{He}$ remains well 10 years after treatment, with no evidence of either sarcoidosis or plasmacytoma.

CASE 4

A 24 year old white man presented with dry cough, acute uveitis, malaise, and weight loss. A chest $x$ ray showed hilar lymphadenopathy. Histology of a scalene lymph node confirmed the diagnosis of sarcoidosis. The symptoms regressed spontaneously, but five years later the patient developed anaemia, splenomegaly and lymphocytosis $\left(8 \times 10^{9} / 1\right)$. He received a course of steroids with no response. He became transfusion dependent and underwent splenectomy. The lymphocyte count continued to rise to $60 \times 10^{9} / 1$. The majority of cells were large granular lymphocytes with a $\mathrm{CD} 2+, \mathrm{CD} 3+$, $\mathrm{CD} 8+, \mathrm{CD} 4-, \mathrm{CD} 16+, \mathrm{CD} 56+, \mathrm{CD} 25+$ phenotype. DNA analysis demonstrated rearrangement of the $T$ cell receptor (TCR) 
Table 1 Summary of clinical features at diagnosis

\begin{tabular}{|c|c|c|c|c|c|c|c|c|}
\hline $\begin{array}{l}\text { Case } \\
\text { number }\end{array}$ & $\begin{array}{l}\text { Sexlage } \\
\text { (years) }\end{array}$ & $\begin{array}{l}\text { Clinical } \\
\text { presentation }\end{array}$ & $\begin{array}{l}\text { Biopsy } \\
\text { site }\end{array}$ & $\begin{array}{l}\text { Other clinical } \\
\text { features }\end{array}$ & $\begin{array}{l}\text { Laboratory tests } \\
\text { for sarcoidosis }\end{array}$ & Treatment & $\begin{array}{l}\text { Response to } \\
\text { treatment }\end{array}$ & $\begin{array}{l}\text { Time } \\
\text { interval }\end{array}$ \\
\hline $\begin{array}{l}1 \\
2\end{array}$ & $\begin{array}{l}M / 65 \\
F / 28\end{array}$ & $\begin{array}{l}\text { Hilar mediastinal nodes } \\
\text { Hilar mediastinal nodes }\end{array}$ & $\begin{array}{l}\text { Mediastinal lymph node } \\
\text { Mediastinal lymph node }\end{array}$ & $\begin{array}{l}\text { None } \\
\text { Skin } \\
\text { Eve }\end{array}$ & $\begin{array}{l}\text { Normal } \\
\text { Normal }\end{array}$ & $\begin{array}{l}\text { None } \\
\text { Prednisolone }\end{array}$ & $\overline{\text { No }}$ & $\begin{array}{l}24 \text { months } \\
18 \text { months }\end{array}$ \\
\hline 3 & $\mathrm{M} / 34$ & Peripheral nodes and lung & Epitrocheal lumph node & $\begin{array}{l}\text { Skin } \\
\text { Eye } \\
\text { Joints }\end{array}$ & Normal & Prednisolone & Yes & 28 years \\
\hline $\begin{array}{l}4 \\
5\end{array}$ & $\begin{array}{l}M / 24 \\
M / 47\end{array}$ & $\begin{array}{l}\text { Hilar nodes } \\
\text { Hilar and mediastinal nodes } \\
\text { and lung }\end{array}$ & $\begin{array}{l}\text { Scalene lymph node } \\
\text { Lung }\end{array}$ & $\begin{array}{l}\text { None } \\
\text { None }\end{array}$ & $\begin{array}{l}\text { Normal } \\
\text { Normal }\end{array}$ & $\begin{array}{l}\text { None } \\
\text { Prednisolone }\end{array}$ & $\overline{\text { Yes }}$ & $\begin{array}{l}8 \text { years } \\
36 \text { months }\end{array}$ \\
\hline
\end{tabular}

$\beta$ chain gene. A diagnosis of large granular lymphocytic (LGL) leukaemia was made and the patient was treated with cyclosporin A with no response but achieved a complete response to deoxycoformycin. $\mathrm{He}$ is alive seven years after the diagnosis. The initial biopsy specimen was not available for review, but re-examination of the spleen showed extensive red pulp infiltration by a monomorphic mature CD3+ lymphoid cell population with abundant cytoplasm, features consistent with LGL leukaemia (fig 3).

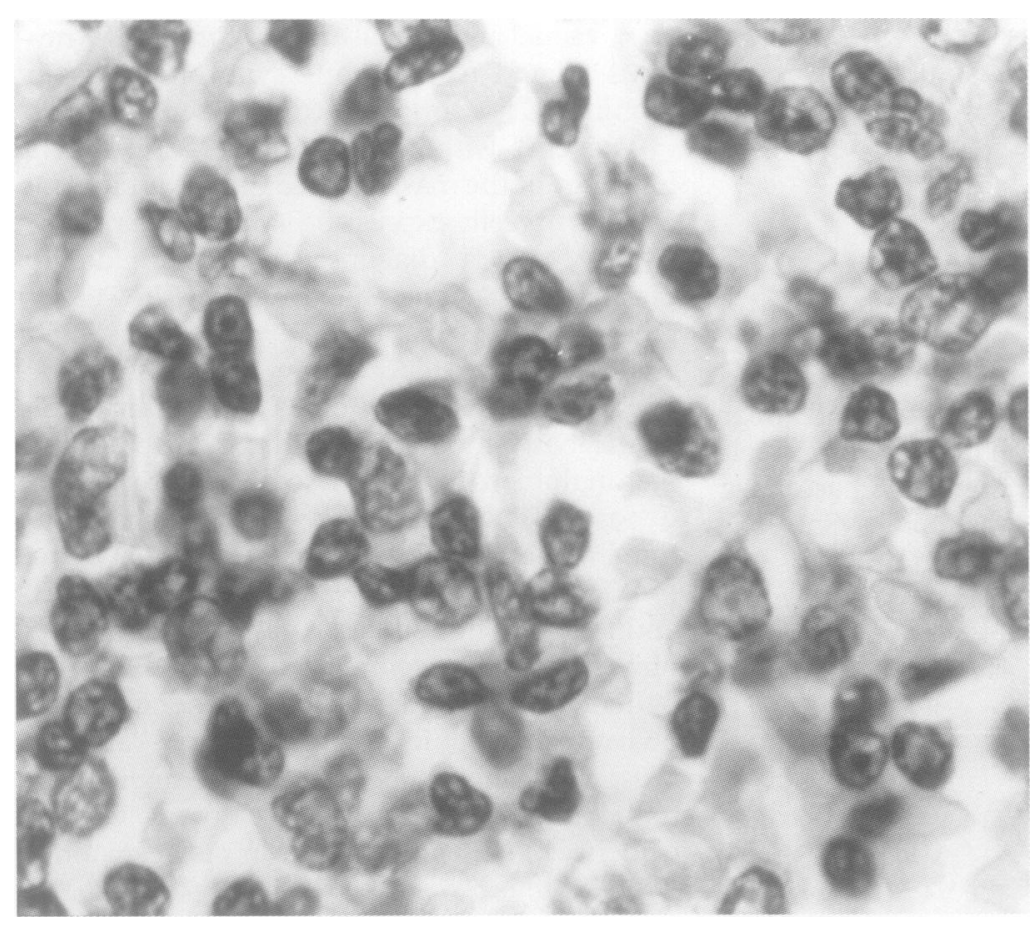

Figure 3 Spleen section from case 4 showing infiltration by mature lymphoid cells.

Table 2 Summary of histology

\begin{tabular}{llll}
\hline Case number & Year & Biopsy site & Diagnosis \\
\hline 1 & 1988 & Mediastinal lymph node & \\
2 & 1990 & Supraclavicular lymph node & Lymphoplasmacytic/lymphoma \\
& 1990 & Mediastinal lymph node & Sarcoidosis \\
3 & 1991 & Mediastinal lymph node & Hodgkin's disease/nodular sclerosis \\
& 1958 & Epitrocheal lymph node & Sarcoidosis \\
& 1968 & Skin nodule & Sarcoidosis \\
& 1977 & Synovium & Sarcoidosis \\
4 & 1985 & Mesenterium & Plasmacytoma \\
& 1985 & Kidney & Sight chain disease \\
& 1978 & Scalene lymph node & Sarcoidosis \\
5 & 1989 & Spleen & Large granular/lymphocytic \\
& 1986 & Lung & Sarcoidosis \\
& 1991 & Spleen & Mantle cell lymphoma \\
& 1991 & Mesenteric lymph node & Mantle cell lymphoma \\
\hline
\end{tabular}

CASE 5

A 47 year old white man presented with shortness of breath. A chest $x$ ray showed hilar and paratracheal lymphadenopathy and lung shadows. A transbronchial biopsy specimen was consistent with sarcoidosis. The patient was treated with prednisolone and went into clinical remission. Four years later, he complained of night sweats, weight loss and fever. Blood counts showed lymphocytosis $\left(5 \times 10^{9} /\right.$ 1). Immunophenotyping demonstrated a clonal B cell phenotype: $\operatorname{IgM}+, \kappa+, \lambda-, \mathrm{CD} 19+$, $\mathrm{CD} 22+, \mathrm{CD} 37+, \mathrm{CD} 5+, \mathrm{FMC} 7+$, and $\mathrm{CD} 2-$. Cytogenetic analysis of the lymphocytes showed an abnormal clone carrying the translocation $t(11 ; 14)(\mathrm{q} 13 ; \mathrm{q} 32)$. A CT scan revealed mediastinal, hilar and abdominal lymphadenopathy and splenomegaly. He received six cycles of CHOP (cyclophosphamide, adriamycin, vincristine, prednisolone) with no response and underwent splenectomy. Review of the spleen and the lymph node showed diffuse infiltration by medium sized lymphoid cells with cleaved nuclei and dispersed chromatin (fig 4A). In addition, there were numerous non-caseating granulomas (fig 4B). The findings were consistent with mantle cell lymphoma coexistent with sarcoidosis. The patient had further chemotherapy with no response and died of progressive disease.

\section{Results}

Table 1 summarises the clinical features of the five patients. There were four men and one woman with a median age at presentation of sarcoidosis of 37 years. All patients presented with hilar lymphadenopathy and four of five (cases 1, 2, 4, and 5) also had mediastinal lymphadenopathy. Three patients had more widespread disease with pulmonary parenchymal involvement (cases 3 and 5), acute uveitis (cases 2 and 4 ) and erythema nodosum (case 2). The other two patients were considered to have chronic sarcoidosis, one (case 5) progressing with pulmonary disease and the other (case 3 ) with chronic keratoconjunctivitis, recurrent parotid swelling, joint involvement, and skin nodules. Three of the patients were treated with steroids, with no response in one (case 2) and transient control in the other two (cases 3 and 5). One of them (case 5), after an initial response, had evidence of disease recurrence with no further response to steroids, but progression of the sarcoidosis in parallel with the lymphoma. Biochemical findings supporting the diagnosis of sarcoidosis 


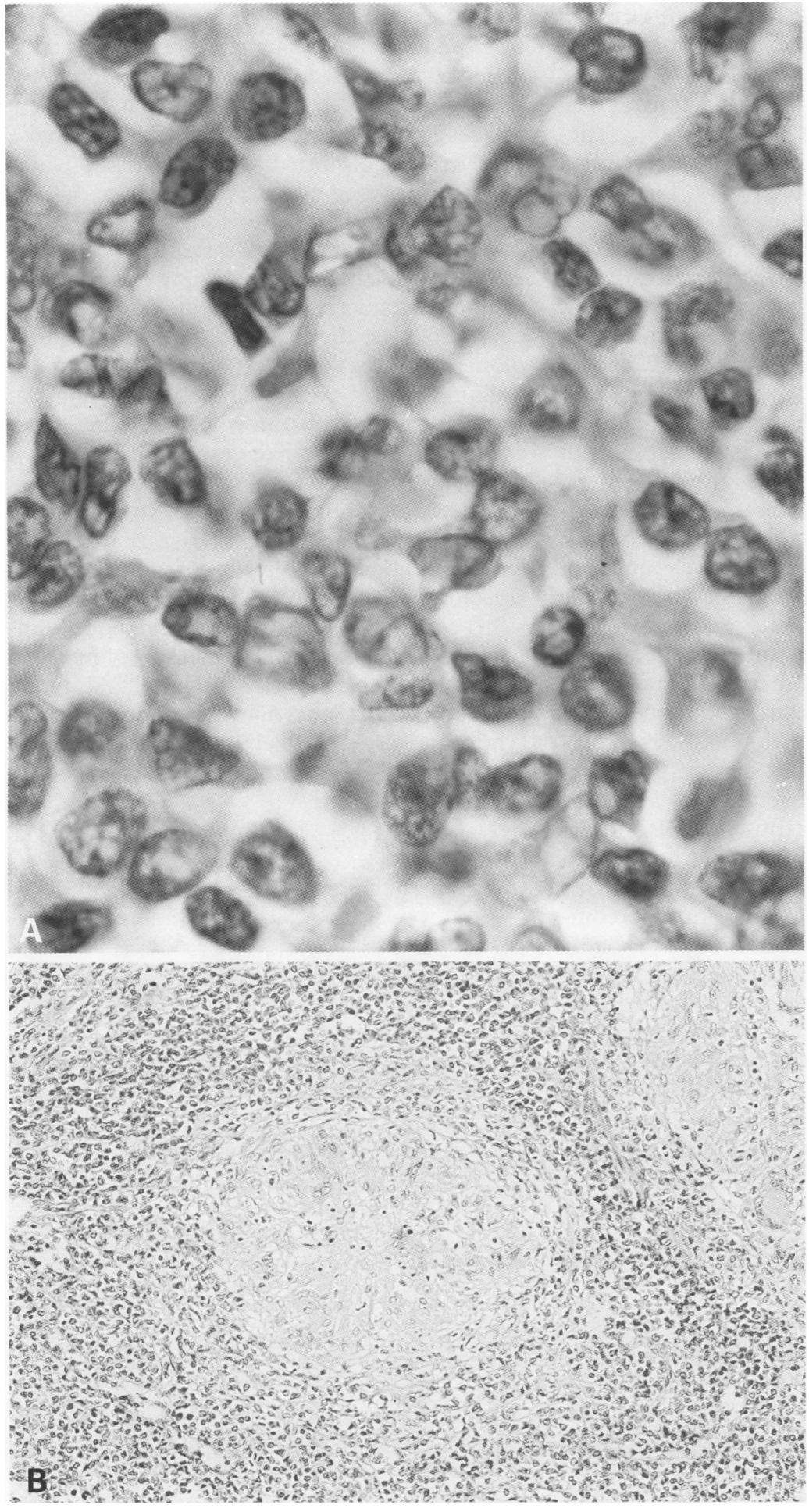

Figure $4 A$, Spleen section from case 5 showing infiltration by medium sized cells, some with an indented nucleus; $B$, lower power view of the spleen showing the coexistence of lymphoma and a non-caseating granuloma.

at presentation (Kviem test, hypercalcaemia) were not identified in any case. The time interval from the onset of sarcoidosis to the development of lymphoma ranged from 18 months to 28 years (table 1). Table 2 summarises the histology of the five patients.

\section{Discussion}

Four of the five cases had a well documented history of sarcoidosis before the development of lymphoma. In one patient (case 1), however, review of the original biopsy specimen revealed that he had lymphoma all along, with noticeable reactive granuloma formation. This case illustrates a common problem in the diagnosis of sarcoidosis. The presence of granulomas in a lymph node biopsy specimen is not specific to sarcoidosis as sarcoid-like granulomas can be found in chronic inflammatory, infectious and neoplastic diseases, including non-Hodgkin's lymphoma and Hodgkin's disease. ${ }^{16-8}$ The diagnosis of sarcoidosis is usually based on a combination of clinical, biochemical and histological findings. Therefore, before such a diagnosis is made the histology should be carefully examined to rule out lymphoma or another underlying condition associated with reactive granuloma formation, or both.

Epidemiological studies have confirmed that there is an increase in the incidence of lymphomas in patients with a history of sarcoidosis. In a series of 2544 patients with sarcoidosis, Brickner and Wilbek ${ }^{9}$ reported an incidence of lymphoid disorders about 11.5 higher than expected. However, the same authors, in a subsequent study based on $18 \%$ of the Danish population, estimated that the incidence was $5 \cdot 5$ higher than expected. The only other malignancy occurring with greater frequency in the same population was lung cancer $(3 \cdot 5 / 1){ }^{10}$

The existence of this syndrome has been challenged after review of the records of the 48 cases initially identified. ${ }^{112}$ However, in the literature reports continue to appear of lymphomas and acute myeloid leukaemias associated with sarcoidosis, suggesting an increased association between the two diseases. ${ }^{13-16}$

Four of our patients (cases 2-5) represent what was described as "sarcoidosis-lymphoma" syndrome. ${ }^{10}$ The three main features characteristic of the syndrome are: (1) the lymphoid malignancy occurs after a preceding history of sarcoid; (2) the median age of onset of sarcoidosis is 10 years above that of unselected patients with sarcoid; (3) Hodgkin's disease occurs more frequently than other types of lymphoma. Brickner also suggested that the chronic type of sarcoidosis is more often associated with lymphoma, and that lymphopenia and treatment with steroids are predisposing factors for its development. ${ }^{10}$

Although the number of cases described here is too small to draw conclusions, not all the features of our patients were reported by others. In agreement with Brickner's observations, three of four patients had been treated with steroids and two had progressive chronic disease. The time interval from the onset of sarcoidosis to the development of lymphoma was shorter in the cases with Hodgkin's and mantle cell lymphoma (18 and 36 months, respectively). This is in agreement with the previous observations that Hodgkin's and nonHodgkin's lymphoma occur earlier than chronic lymphocytic leukaemia and paraproteinaemias, and might reflect the different natural history of these lymphoid malignancies. ${ }^{10}$

In contrast to the published data, the median age of our patients at the time of onset of sarcoidosis was 37 years, not older than that expected for the unselected population with 
sarcoidosis. The lymphomas were of different subtypes: plasmacytoma, mantle cell and LGL leukaemia. To our knowledge, this is the first case of LGL leukaemia reported following sarcoidosis. In contrast to the lymphomas described in the literature and those included here, which are all of B cell origin, LGL leukaemia is a neoplastic disease of $\mathrm{T}$ cell origin. Reactive granuloma formation, although absent in this case, is a relatively frequent histological finding in the spleens from patients with LGL (Dr I A Lampert, unpublished observations), although the significance of this finding is unclear.

The causal relation between sarcoidosis and lymphoma is still a subject of speculation, but it is likely that there are several pathogenetic mechanisms involved. There is enough evidence to support the hypothesis that sarcoidosis is a predisposing factor for the development of a secondary lymphoid malignancy due to the disturbances of the immune system. In sarcoidosis there is a well documented increase in $\mathrm{CD} 4+\mathrm{T}$ cells and a numerical reduction in $\mathrm{CD} 8+\mathrm{T}$ cells within the affected tissues. The CD4 + cells express activation markers (interleukin-2 receptor, HLA-DR) and respond vigorously in vitro to mitogenic and antigenic stimulation and spontaneously release interleukin-2 and interferon- $\alpha .^{1718}$ The number of B lymphocytes is unaffected and the raised circulating antibody levels and immune complexes in some of these patients most probably reflect a secondary $B$ cell stimulation. ${ }^{2}$ In addition, there is an increased antigenic presentation by the dendritic cells with release of cytokine mediators such as interleukin-1 and tumour necrosis factor- $\alpha$ (TNF- $\alpha)$ as well as oxidants. ${ }^{1017}$ Recent studies have shown that alveolar macrophages strongly express the B2 integrin CD11b and its ligand intercellular adhesion molecule-1; this may result from cytokine stimulation, particularly of TNF- $\alpha$, and participates in the activation of $T$ cells by the antigen presenting cells. ${ }^{3}$

The low number of CD8 $+\mathrm{T}$ cells has been interpreted as indicating dysfunction in the immunoregulatory pathways leading to the formation of granulomas. The model that has been proposed is that sarcoidosis is a local cell mediated immune response induced by unknown antigens resulting in the activation of CD4 + cells in an environment lacking significant numbers of regulatory CD8 + cells. These circumstances would lead to the formation of granulomas as cytokines released by the activated lymphocytes react and stimulate macrophages. ${ }^{10}$ It is not unreasonable to assume that in an environment with defective regulation by suppressor $\mathrm{T}$ cells, a clone may escape, resulting in the development of a lymphoid malignancy. In this context chronic sarcoidosis represents a more prolonged and severe form of disease than the acute type and is more likely to be associated with a secondary malignancy. In addition, steroid treatment, by further compromising the immune system, is another predisposing factor that can act synergistically with the above to enhance the malignant process.
Studies of the TCR on alveolar lymphocytes in sarcoidosis by polymerase chain reaction have demonstrated oligoclonal or clonal expansion of a $T$ cell subset. This may represent the response to a predominant antigen by $T$ cells bearing a limited TCR repertoire which become activated and expanded. ${ }^{1920}$

An alternative hypothesis suggested by Reich et $a l^{15}$ states that clinical sarcoidosis is a generalised cell mediated immune response to tumour antigens. It represents the systemic counterpart of the localised sarcoid-like granulomas present within tumours or tumour draining lymph nodes. The above hypothesis would partially explain why true sarcoidosis and reactive sarcoid-like granuloma formation is associated with the same type of lymphomafor example, Hodgkin's disease. It would also explain cases-for example, case 2, where the lymphoma develops shortly after the onset of sarcoidosis.

In conclusion, we present evidence supporting the concept of a sarcoidosis-lymphoma syndrome as described by Brickner. ${ }^{10}$ Although . the pathogenetic mechanisms underlying this syndrome vary, it is likely that at least in some cases sarcoidosis represents a systemic response to tumour antigens.

1 Neville E. Sarcoidosis: the clinical problem. Postgrad Med $f$ 1988;64:531-5.

2 Poulter LW. Immune aspects of sarcoidosis. Postgrad Med f 1988;64:536-43.

3 Striz I, Wang Y-M, Kalaycioglu O, Costabel U. Expression of alveolar macrophage adhesion molecules in pulmonary sarcoidosis. Chest 1992;102:882-6.

4 Pueringer RJ, Schwartz DA, Dayton CS, Gilbert SR, Hunninghake GW. The relationship between alveolar macrophage TNF, IL-1 and PGE2 release, alveolitis and disease phage TNF, IL-1 and PGE2 release, alveolitis and
severity in sarcoidosis. Chest 1993;103:832-8.

5 Pforte A, Schiessler A, Gais P, Beer B, Ehlers M, Schutt $\mathrm{C}$, et al. Expression of CD14 correlates with lung function impairment in pulmonary sarcoidosis. Chest 1994;105: 349-54.

6 Brickner H. Sarcoid reactions and sarcoidosis in Hodgkin's disease and other malignant lymphomata. $\mathrm{Br} \mathcal{F}$ Cancer 1972;26:120-8.

7 Brickner H. Sarcoid reaction in malignant tumours. Cancer Treat Rev 1986a;13:147-56.

8 Kadin ME, Donaldson SS, Dorfman RF. Isolated granulomas in Hodgkin's disease. $N$ Engl $\mathcal{F}$ Med 1970;283: 859-61.

9 Brickner $H$, Wilbek $E$. The incidence of malignant tumours in patients with respiratory sarcoidosis. Br F Cancer 1974; 29:247-51.

10 Brickner $\mathrm{H}$. The sarcoidosis-lymphoma syndrome. $\mathrm{Br} f$ Cancer 1986;54:467-73.

11 Romer FK. Sarcoidosis and cancer - a critical review. In: Jones Williams W, Davies DH, eds. Eighth International Conference on sarcoidosis and other granulomatous diseases. Cardiff: Alpha Omega Publishing, 1980:201-5.

12 Romer FK. Case 7 - 1982. Sarcoidosis and cancer [letter]. N Engl f Med 1982;306:1490.

13 Masuda R, Toyoshima H, Bandou T, Iyosama T, Matsui $\mathrm{Y}$, Takemura T. Malignant lymphoma of the stomach associated with systemic sarcoidosis. Cancer 1992;70: 2592-6.

14 Brennan NJ, Fennelly JJ, Towers RP, Fitzgerald MX. Sarcoidosis and lymphoma in the same patient. Postgrad Med f 1983;59:581-5.

5 Reich J. Acute myeloblastic leukemia and sarcoidosis. Cancer 1985;55:366-9.

16 Mainguene C, Picard O, Audouin J, Le Tourneau A, Jagueux $\mathrm{M}$, Diebold J. An unusual case of mycosis fungoides presenting as sarcoidosis or granulomatous mycosis funpresenting as sarcoidosis or granuloma
coides. Am $\mathcal{F}$ Clin Pathol 1993;99:82-8.

17 Muller-Quernheim J, Pfeifer S, Mannel D, Strausz J, Ferlinz R. Lung-restricted activation of the alveolar macrophage/ monocyte system in pulmonary sarcoidosis. Am Rev Respir monocyte system in pulmo

18 Robinson BWS, McLemore T, Crystal RG. Gamma interferon is spontaneously released by alveolar macrophages and lung T-lymphocytes in patients with pulmonary sarcoidosis. $\mathcal{f}$ Clin Invest 1985;75:1488-95

19 Forman JD, Silver RF, Klein JT, Britt EJ, Scott PP, Schonheld SA, et al. T cell receptor variable b-gene expression in the normal lung and in active pulmonary sarcoidosis. Nature 1991;349:526.

20 Forrester JM, Newman LS, Wang Y, King TE, Kotzin BI. Clonal expansion of lung $\mathrm{Val}+\mathrm{T}$ cells in pulmonary sarcoidosis. f Clin Invest 1993;91:299-300. 